\title{
Esmirtazapine for the Treatment of Chronic Primary Insomnia: A Randomized Long-Term Safety Study in Elderly Outpatients
}

\author{
Neely Ivgy-May ${ }^{1 *}$, Qing Chang ${ }^{1}$, Annpey Pong ${ }^{1}$, Andrew Winokur ${ }^{2}$ \\ ${ }^{1}$ Merck \& Co., Inc., Kenilworth, NJ, \\ ${ }^{2}$ Department of Psychiatry, UConn Health, Farmington, CT, USA
}

Received October 12, 2019

Revised December 21, 2019

Accepted January 3, 2020

Address for correspondence

Neely Ivgy-May, PhD

Merck \& Co., Inc.

2000 Galloping Hill Road,

Kenilworth, NJ 07033, USA

Tel: +1-972-52-672-6671

E-mail: mayneely@gmail.com

*Current affiliation: Shenox Pharmaceuticals, McLean, VA, USA

\begin{abstract}
Objectives: This 52-week, double-blind, randomized, Phase 3 study evaluated the long-term safety of esmirtazapine $1.5 \mathrm{mg}$ and $3.0 \mathrm{mg}$ in elderly outpatients (aged $\geq 65$ years) with insomnia. Methods: Participants were randomized to receive esmirtazapine $1.5 \mathrm{mg}$ or $3.0 \mathrm{mg}$ administered once nightly. Safety and tolerability (primary objectives) were assessed via adverse event (AE) reporting, routine clinical measurements [vital signs; electrocardiogram (ECG); laboratory parameters], and residual-effects assessments. Total sleep time (TST), wake time after sleep onset (WASO), and sleep latency (SL) were assessed (secondary objectives). Results: Of 259 randomized participants, 153 completed treatment. AEs and serious AEs were reported by $89.8 \%$ and $7.0 \%$, respectively, of $1.5 \mathrm{mg}$ recipients, and $88.5 \%$ and $3.8 \%$, respectively, of $3.0 \mathrm{mg}$ recipients. Discontinuations due to AEs were reported in $16.4 \%$ and $18.3 \%$ of participants receiving esmirtazapine $1.5 \mathrm{mg}$ and $3.0 \mathrm{mg}$, respectively. The most frequent AEs (>10\%) were nasopharyngitis, somnolence, dizziness, headache, dry mouth, weight increase, and fatigue. One participant died; the death was judged unrelated to treatment. Elevated eosinophil counts were noted, but not considered clinically significant. No remarkable or clinically relevant changes in laboratory parameters, vital signs, or ECG were observed. There was no evidence of residual effects; alertness at awakening increased by a median of $17(1.5 \mathrm{mg})$ and $15(3.0 \mathrm{mg})$ points from baseline, respectively, and ability to work/function by 12 points (both groups; all $p<0.0001$ ). Improvements from baseline in TST, WASO, and SL were observed. Conclusions: Esmirtazapine was reasonably tolerated in elderly outpatients with insomnia. No significant safety signals were observed.
\end{abstract}

J Sleep Med 2020;17(1):19-30

Key Words: Elderly, Esmirtazapine, Insomnia, Outpatients, Safety.

\section{Introduction}

Insomnia is a highly prevalent disorder, characterized by either non-restorative sleep or difficulties initiating or maintaining sleep, ${ }^{1}$ which affects up to approximately $20 \%$ of adults in the United States (U.S.). ${ }^{2}$ Compromised sleep quality impacts on the daytime functioning of affected individuals, especially in social and occupational domains, leading to impaired overall quality of life and an increased risk of psychiatric comorbidities. ${ }^{3-5}$ The prevalence of insomnia increases with age, with estimates ranging from $20-50 \%$ in the elderly population, ${ }^{6}$ which makes elderly adults the most common users of hypnotic drugs. ${ }^{7}$ Insomnia in the elderly is associated with affective disorders, increased healthcare utilization, ${ }^{8}$ higher risk

This is an Open Access article distributed under the terms of the Creative Commons Attribution Non-Commercial License (https://creativecommons.org/licenses/by-nc/4.0) which permits unrestricted non-commercial use, distribution, and reproduction in any medium, provided the original work is properly cited. of accidents and falls, ${ }^{6,9}$ and cognitive impairment that can be misdiagnosed as dementia. ${ }^{10}$

Currently, first-line pharmacotherapy for insomnia relies on the use of positive allosteric modulators of gamma-aminobutyric acid type $A\left(\mathrm{GABA}_{\mathrm{A}}\right)$ receptors, which induce sedation through the potentiation of the inhibitory signaling of $\mathrm{GABA}_{\mathrm{A}}$ receptors. ${ }^{11,12}$ Although effective in promoting sleep, $\mathrm{GABA}_{\mathrm{A}}$ receptor modulators elicit global inhibitory effects in the central nervous system that make them liable to producing a variety of side effects, including rebound insomnia, memory failure, and abuse potential. ${ }^{11,13}$ Despite being the primary treatments for insomnia in elderly patients, $\mathrm{GABA}_{\mathrm{A}}$ receptor modulators may not be an ideal treatment for this patient population, as they are associated with impairment of motor function and coordination in elderly patients, along with increased rates of falls and motor vehicle crashes. ${ }^{14,15}$

Safety concerns associated with $\mathrm{GABA}_{\mathrm{A}}$ modulators prompt- 
ed the clinical development of sleep-promoting compounds that facilitate sleep via more specific and targeted mechanisms of action, and this was anticipated to translate into an improved side-effects profile. For example, orexin receptor antagonists (ORAs) have been developed to promote sleep by blocking physiological effects of the orexin compounds, which are key mediators in the maintenance of arousal and vigilance. ${ }^{16}$ The ORA suvorexant has demonstrated sleep-promoting effects with minimal residual next-day somnolence or psychomotor impairment in clinical studies, including in elderly insomnia patients. ${ }^{7,17-20}$ Other pharmacological treatments for insomnia include selective antagonists of histamine $\mathrm{H} 1$ and $\alpha_{1}$-adrenergic receptors, antidepressants and antipsychotic drugs, which are typically prescribed off-label, melatonin receptor agonists, and over-the-counter antihistamines. ${ }^{11}$ Non-pharmacological therapies, such as cognitive behavioral therapy, have also shown efficacy as an alternative to pharmacotherapy. ${ }^{21}$

Treatment with low doses of sedating antidepressants may be a promising approach for those patients who are more likely to experience sleep-maintenance insomnia, such as the elderly. Antidepressants have relatively discrete activity and act by modulating neurotransmitters, such as histamine, serotonin, and norepinephrine. ${ }^{22}$ To date, low doses ( 3 and $6 \mathrm{mg}$ ) of the antidepressant doxepin (Silenor ${ }^{\mathrm{TM}}$, Currax Pharmaceuticals LLC, Morristown, NJ, USA), a modulator of the histamine H1 receptor, have been approved in the U.S. for the treatment of insomnia characterized by difficulties with sleep maintenance. ${ }^{23}$ At low doses, doxepin demonstrated efficacy in improving sleep maintenance and was associated with a favorable safety profile in both younger (aged 18-64 years) ${ }^{24}$ and older (aged $\geq 65$ years) adults. ${ }^{25}$ Several other antidepressants have been prescribed off-label in the management of insomnia, but the scientific evidence supporting their use is weak. ${ }^{26}$

Mirtazapine is an antidepressant with sleep-promoting properties $^{27,28}$ that acts via antagonism of histamine $\mathrm{H} 1$ receptors, $5-\mathrm{HT}_{2}$ and $5-\mathrm{HT}_{3}$ serotonergic receptors, and adrenergic $\alpha 2-$ autoreceptors. ${ }^{29}$ It is a racemic mixture of $\mathrm{S}(+)$ and $\mathrm{R}(-)$ enantiomers, with the former characterized by a shorter half-life compared with the latter. The maleic salt of $\mathrm{S}(+)$ mirtazapine, referred to as esmirtazapine, was advanced to the clinical phase as an investigational therapy for insomnia based on the consideration that the shorter half-life of esmirtazapine $(10 \mathrm{~h})$ relative to the racemic mixture (range: 20 to $40 \mathrm{~h}^{30}$ ) would diminish risk of the emergence of associated side effects, in particular residual next-day effects. In clinical studies, acute (2-day) and 2- and 6-week treatment with esmirtazapine in non-elderly participants (aged 18 to $<65$ years) with insomnia demonstrated significant improvements in objective and subjective sleep measures at doses of $1.5 \mathrm{mg}, 3.0 \mathrm{mg}$, and $4.5 \mathrm{mg}$ relative to placebo, and was generally well tolerated, with minimal re- sidual daytime effects ${ }^{31-34}$ and no signs of rebound insomnia. ${ }^{31,32}$

Given the burden of insomnia and the high prevalence of sleep-aid use in the geriatric population, the current study was conducted in elderly outpatients (aged $\geq 65$ years) with chronic primary insomnia. The primary objective was to investigate the safety and tolerability of long-term (52-week) treatment with esmirtazapine at doses of $1.5 \mathrm{mg}$ and $3.0 \mathrm{mg}$. The secondary objective was to collect exploratory efficacy data with respect to sleep improvement.

\section{Methods}

\section{Study design and treatments}

This Phase 3 study (Merck \& Co., Inc., Kenilworth, NJ, USA, Protocol Number 176005; NCT00561574) was part of the esmirtazapine clinical development program. Since this study was conducted, the sponsor (Merck Sharp \& Dohme Corp., a subsidiary of Merck \& Co., Inc.) discontinued further development of esmirtazapine. The study was conducted between January 2008 and February 2010 in 32 centers across Canada, Denmark, Finland, Germany, the Netherlands, Sweden, and the U.S. The trial was carried out in compliance with the ethical principles of the Declaration of Helsinki and in accordance with the International Conference on Harmonisation guidelines for Good Clinical Practice, as well as applicable local regulatory requirements. The study was approved by the appropriate Institutional Ethics Committee or Review Board. Participants were required to sign an informed consent form after receiving an explanation of the scope and nature of the investigation.

This was a randomized, double-blind, parallel-group (assignment to two doses of esmirtazapine), multisite study undertaken in elderly participants over a period of 52 weeks. The study design comprised a 14-day screening process during which participants' eligibility for the study was ascertained based on prespecified inclusion criteria (Fig. 1). This was followed by randomization (Day 1) using an Interactive Response (telephone) system, which assigned a 6-digit randomization number to eligible participants. Participants were randomized to receive either $1.5 \mathrm{mg}$ or $3.0 \mathrm{mg}$ esmirtazapine (manufactured by NV Organon, Oss, The Netherlands, a subsidiary of Merck \& Co., Inc.) before bedtime for a treatment duration of 364 days (52 weeks). Participant visits occurred at the end of Weeks 1,2, and 4 during the first month of the trial, and every 4 weeks thereafter. A follow-up visit was scheduled 1 week after study completion or premature discontinuation. A telephone call was scheduled 30 days after the last dose to follow-up on any adverse events (AEs) occurring after the follow-up visit. 


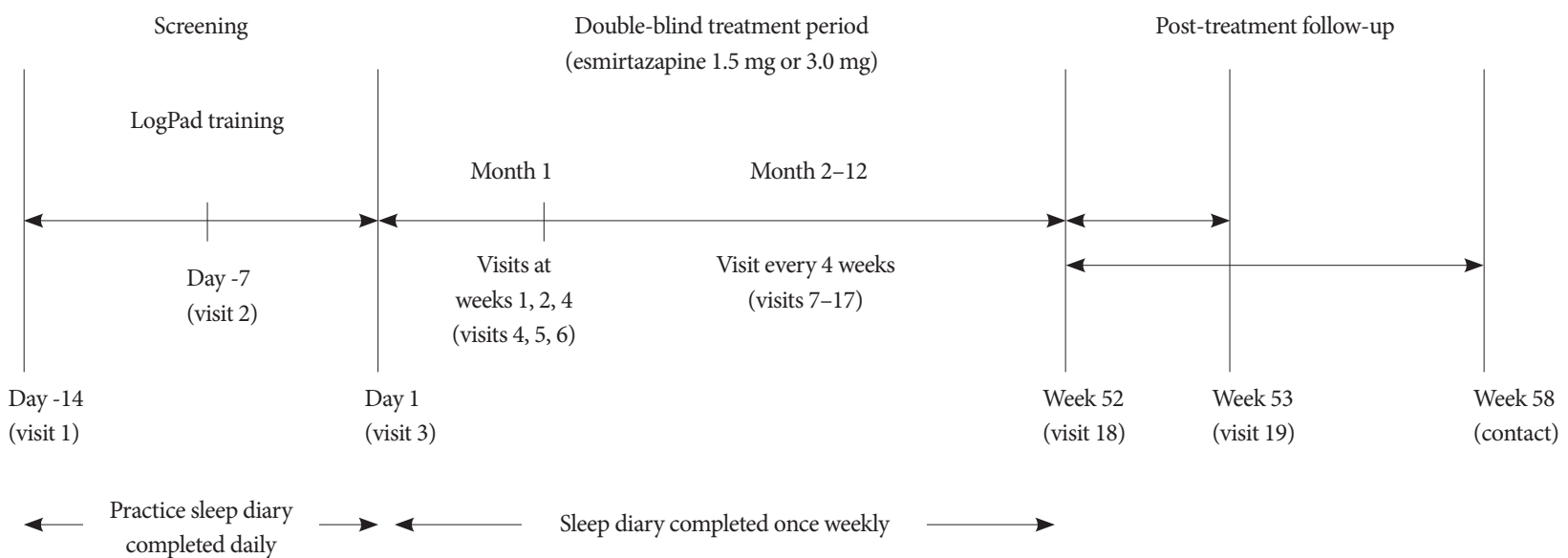

Figure 1. Study design.

\section{Participants}

Eligible participants were aged $\geq 65$ years at screening and had a normal bedtime within the 21:00-01:00-hours range, with variations not exceeding $2 \mathrm{~h}$ for five out of seven nights. Participants were required to demonstrate the ability to independently complete a sleep questionnaire in the week preceding randomization using the LogPad, a handheld electronic data-recording device that captures the sleep diary with respect to subjective drug-efficacy parameters and measures of drug residual effects. Further, participants had a documented diagnosis of chronic primary insomnia according to the Diagnostic and Statistical Manual of Mental Disorders, 4th Edition, Text Revision (DSM-IV-TR) criteria for primary insomnia (DSM-IV-TR 307.42) with a duration of $\geq 1$ month, and met the following criteria based on medical or sleep history for at least 3 nights per week for at least 1 month: total sleep time $(\mathrm{TST}) \leq 6.5 \mathrm{~h}$; wake time after sleep onset (WASO) $\geq 60 \mathrm{~min}$; and sleep latency $(\mathrm{SL}) \geq 30 \mathrm{~min}$.

Participants with other sleep disorders based on DSM-IVTR criteria, those presenting with sleep disturbances caused by significant medical or DSM-IV-TR psychiatric illness, and those who were currently, or within the last 2 years had been, diagnosed or treated for depression were excluded. Participants with signs of dementia or other serious cognitive impairment, defined as a score of $<26$ on the Mini-Mental State Examination, were also excluded.

\section{Safety and tolerability evaluations}

The safety and tolerability analyses (primary objective) were performed in the all-participants-treated population, which was defined as all participants who received at least one dose of trial medication. Recording of AEs was performed from signing the informed consent form until 30 days after end of treatment. Clinical examinations evaluating vital signs and body weight were conducted at screening (Day -14) and at every vis- it, including the 7-day follow-up visit. Physical examinations were scheduled at screening (Day -14) and Week 52. In addition, electrocardiogram (ECG) was assessed at Days -14 and -7 and Weeks 2, 24, and 52, and laboratory parameters, including hematology, biochemistry, and urinalysis, were evaluated at screening and Weeks 2, 4, 12, 24, 36, and 52.

Residual effects (special safety measures) were assessed based on a sleep diary completed weekly on the LogPad from Day 1 until Week 52. The sleep diary captured participants' ratings of alertness at awakening, energy level, and ability to work/ function during the day on visual analog scales (VAS) from 0-100 mm. Participants also reported their tendency to nap during the day ("Yes/No") and indicated the napping time per day (in $\mathrm{h}$ and $\mathrm{min}$ ).

\section{Efficacy evaluations}

Exploratory efficacy evaluations (secondary objective) were performed in the intent-to-treat population of all randomized participants who received at least one dose of trial medication and had at least one recorded post-baseline efficacy measurement on the weekly sleep diary. Efficacy measures included TST, WASO, SL, number of awakenings, and sleep quality based on weekly sleep diaries completed from Day 1 until Week 52. In addition, the extent of sleep difficulties was assessed on Day -7 and Weeks 2, 4, 12, 24, 36, and 52 using the insomnia severity index (ISI) based on participant ratings. The investigator global rating (IGR) scale was used by the clinician to rate insomnia symptom severity [IGR-severity (IGR-S)] and the therapeutic effect of the treatment regimen. These evaluations were completed at Day -7 (IGR-S score only) and Weeks 2, 4, 12, 24, 36, and 52.

\section{Statistical methods}

Safety and efficacy parameters were evaluated using summary and descriptive statistics, respectively, with changes from 
baseline where appropriate. Continuous variables were analyzed by summary statistics. Paired t-statistics were used for testing the change from baseline by visit and by week as an exploratory analysis for efficacy endpoints. The ratings on the weekly sleep diary collected at Day 1 were used as baseline. No primary or secondary hypotheses for the testing of either efficacy or safety were performed. Categorical endpoints were summarized by treatment group, and summary statistics included sample size and percent for each response category. The denominator for percentage calculations was the total number of participants with non-missing values within each treatment group in that specific time point.

Data from weekly sleep diaries were analyzed using the last observation carried forward (LOCF) approach; sensitivity analyses were conducted based on observed case (OC) data. As the primary objective of this study was to assess long-term safety, the efficacy analysis is presented descriptively and with $p$ values as exploratory analyses.

The planned number of participants was based on the need to collect long-term safety data in elderly patients. Assuming a discontinuation rate of $50-80 \%$, a sample size of 250 participants was considered sufficient. A sample size of 130 participants in each group would have an effect size of 1.1 to detect a difference in means of $86 \mathrm{~min}$ for TST duration, assuming the common standard deviation was 80 min using a two-sample $\mathrm{t}$-test with a 5\% two-sided significance level.

\section{Results}

\section{Participants}

Of the 348 participants screened for this trial, 259 were randomized and treated, with 128 participants allocated to the 1.5-mg esmirtazapine treatment group and 131 participants assigned to the 3.0-mg treatment group (Fig. 2). A total of 153 participants (59.1\%) completed the study, while 106 participants discontinued prematurely: 48 participants in the $1.5-\mathrm{mg}$ group and 58 participants in the 3.0-mg group. A total of 173 participants were exposed to at least 6 months of treatment, including $82(62.6 \%)$ in the 3.0-mg group and $91(71.1 \%)$ in the 1.5-mg group. AEs were the most common reason for discontinuation [21 participants (16.4\%) in the 1.5-mg group and 24 participants (18.3\%) in the 3.0-mg group]. Insufficient therapeutic effect was the next most common reason for discontinuation and was more prevalent in the 3.0-mg group [21 participants $(16.0 \%)$ ] than the 1.5-mg group [11 participants $(8.6 \%)]$.

The majority of participants were female $(62.5 \%)$, white (97.7\%), and of non-Hispanic/Latino descent (97.7\%), with a mean (standard deviation) age of $70.9( \pm 5.2)$ years, and a mean body mass index (BMI) of $26.9( \pm 3.8) \mathrm{kg} / \mathrm{m}^{2}$. The most reported BMI category was overweight (43.2\%) (Table 1).

\section{Safety and tolerability}

A total of 231 participants experienced at least one AE during the in-treatment period, including 115 participants (89.8\%) in the $1.5-\mathrm{mg}$ group and 116 participants (88.5\%) in the $3.0-\mathrm{mg}$ group (Table 2). AEs judged by the investigators to be treatment-related were more frequently reported in the $3.0-\mathrm{mg}$ group [88 participants $(67.2 \%)$ ] than the 1.5-mg group [74 participants (57.8\%)]. The most frequent AEs, with an incidence of $>10 \%$, were nasopharyngitis, somnolence, dizziness, headache, dry mouth, weight increase, and fatigue. Somnolence $(26.7 \%$ vs. $11.7 \%)$, dizziness ( $14.5 \%$ vs. $9.4 \%)$, dry mouth (10.7\% vs. $7.8 \%$ ), and weight increase ( $15.3 \%$ vs. $8.6 \%$ ) occurred more commonly in the $3.0-\mathrm{mg}$ group vs. the $1.5-\mathrm{mg}$ group. The majority of cases of somnolence, dizziness, dry mouth, weight

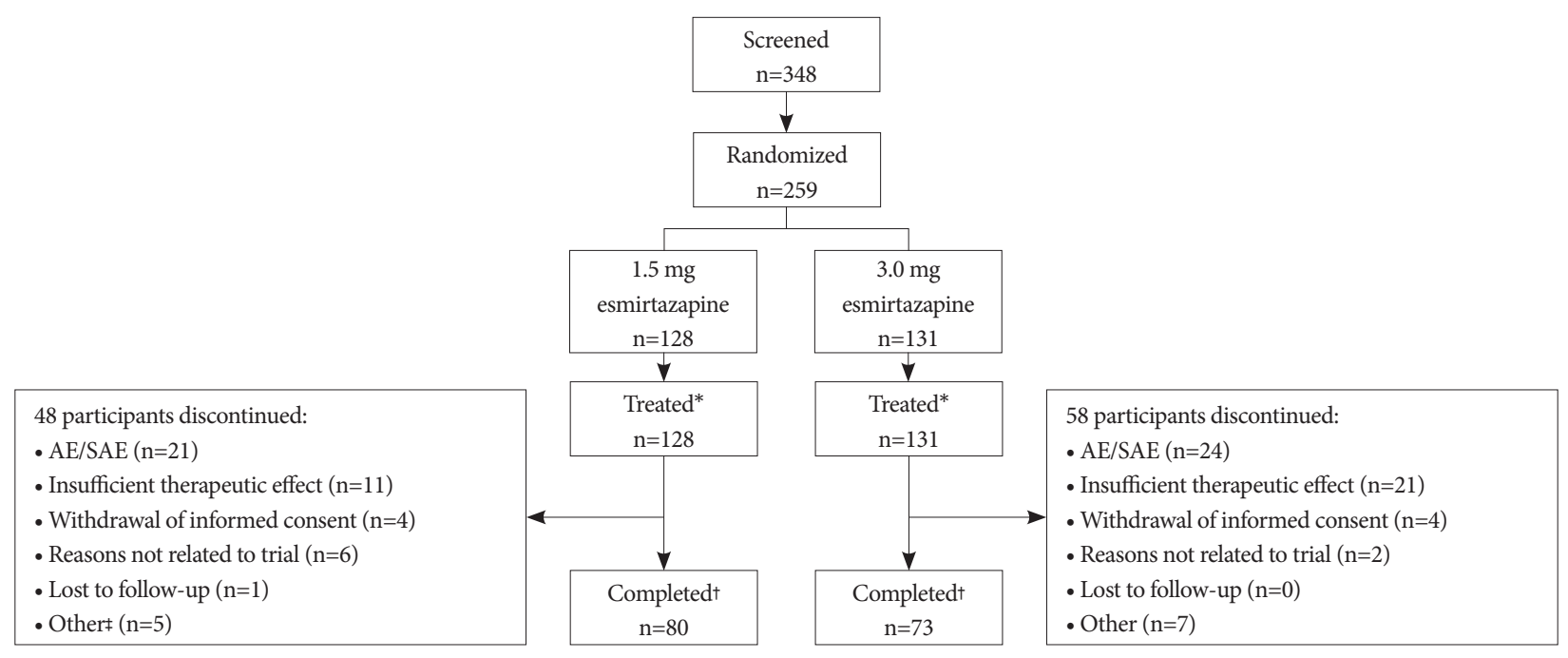

Figure 2. Participant disposition. *participants took at least one dose of trial medication, tinformation as per End of Trial Form, ‡one participant in the 1.5-mg group discontinued due to lack of compliance with study diary. AE: adverse event, SAE: serious AE. 
Table 1. Participant demographics at screening

\begin{tabular}{|c|c|c|c|}
\hline Variables & $\begin{array}{c}\text { Esmirtazapine } \\
1.5 \mathrm{mg} \\
(\mathrm{n}=128)\end{array}$ & $\begin{array}{c}\text { Esmirtazapine } \\
3.0 \mathrm{mg} \\
(\mathrm{n}=131)\end{array}$ & $\begin{array}{c}\text { Total } \\
(\mathrm{n}=259)\end{array}$ \\
\hline \multicolumn{4}{|l|}{ Age (years) } \\
\hline Median (range) & $\begin{array}{c}69.0 \\
(65.0-86.0)\end{array}$ & $\begin{array}{c}70.0 \\
(65.0-87.0)\end{array}$ & $\begin{array}{c}69.0 \\
(65.0-87.0)\end{array}$ \\
\hline Mean (SD) & $70.7(5.2)$ & $71.1(5.1)$ & $70.9(5.2)$ \\
\hline \multicolumn{4}{|l|}{ Height $(\mathrm{cm})$} \\
\hline Median (range) & $\begin{array}{c}165.0 \\
(139.7-198.1)\end{array}$ & $\begin{array}{c}166.4 \\
(144.0-188.0)\end{array}$ & $\begin{array}{c}166.0 \\
(139.7-198.1)\end{array}$ \\
\hline Mean (SD) & $167.3(10.5)$ & $167.4(9.7)$ & $167.4(10.1)$ \\
\hline \multicolumn{4}{|l|}{ Weight (kg) } \\
\hline Median (range) & $\begin{array}{c}73.7 \\
(48.6-124.3)\end{array}$ & $\begin{array}{c}75.0 \\
(45.3-107.0)\end{array}$ & $\begin{array}{c}73.9 \\
(45.3-124.3)\end{array}$ \\
\hline Mean (SD) & $76.1(15.8)$ & $75.5(13.2)$ & $75.8(14.5)$ \\
\hline \multicolumn{4}{|l|}{ Gender, n (\%) } \\
\hline Female & $83(64.8)$ & $79(60.3)$ & $162(62.5)$ \\
\hline Male & $45(35.2)$ & $52(39.7)$ & $97(37.5)$ \\
\hline \multicolumn{4}{|l|}{ Race, n (\%) } \\
\hline $\begin{array}{l}\text { Black or African- } \\
\text { American }\end{array}$ & $4(3.1)$ & $2(1.5)$ & $6(2.3)$ \\
\hline White & $124(96.9)$ & $129(98.5)$ & $253(97.7)$ \\
\hline \multicolumn{4}{|l|}{ Ethnicity, n (\%) } \\
\hline $\begin{array}{l}\text { Hispanic or } \\
\text { Latino }\end{array}$ & $2(1.6)$ & $4(3.1)$ & $6(2.3)$ \\
\hline $\begin{array}{l}\text { Not Hispanic or } \\
\text { Latino }\end{array}$ & $126(98.4)$ & $127(96.9)$ & $253(97.7)$ \\
\hline \multicolumn{4}{|l|}{ BMI $\left(\mathrm{kg} / \mathrm{m}^{2}\right)$} \\
\hline Median (range) & $\begin{array}{c}26.3 \\
(17.9-35.8)\end{array}$ & $\begin{array}{c}26.6 \\
(19.2-35.4)\end{array}$ & $\begin{array}{c}26.5 \\
(17.9-35.8)\end{array}$ \\
\hline Mean (SD) & $27.0(4.0)$ & $26.9(3.7)$ & $26.9(3.8)$ \\
\hline \multicolumn{4}{|l|}{ BMI category, n (\%) } \\
\hline $\begin{array}{l}\text { Underweight } \\
(\mathrm{BMI}<18.5)\end{array}$ & $1(0.8)$ & $0(0.0)$ & $1(0.4)$ \\
\hline $\begin{array}{l}\text { Normal range } \\
(18.5 \leq \mathrm{BMI}<25)\end{array}$ & $43(33.6)$ & $43(32.8)$ & $86(33.2)$ \\
\hline $\begin{array}{l}\text { Overweight } \\
(25 \leq \mathrm{BMI}<30)\end{array}$ & $55(43.0)$ & $57(43.5)$ & $112(43.2)$ \\
\hline Obese $(\mathrm{BMI} \geq 30)$ & $29(22.7)$ & $31(23.7)$ & $60(23.2)$ \\
\hline
\end{tabular}

BMI: body mass index, SD: standard deviation

increase, and fatigue were considered treatment-related by the investigator (Table 2). Approximately $10 \%$ of the participants in both the 1.5-mg and 3.0-mg groups experienced AEs of severe intensity, including one event of dizziness and one event of fatigue in the 1.5-mg treatment group, and one event of somnolence, one event of fatigue, and two events of dry mouth in the 3.0-mg group, which were considered probably or possi- bly drug-related.

One participant in the 1.5-mg treatment group died due to narcotic intoxication. The autopsy report indicated a history of asthma, heroin abuse, recent depression, and remote hand injuries. Toxicological studies were positive for ethanol and morphine. Based on these findings, the cause of death was described as morphine toxicity with arteriosclerotic cardiovascular disease listed as a contributing condition. The death was judged as unlikely to be related to study drug by the investigator and the sponsor.

During the in-treatment period, a total of 13 serious AEs (SAEs) were reported in nine participants $(7.0 \%)$ in the $1.5-\mathrm{mg}$ group, and seven SAEs were reported in five participants (3.8\%) in the 3.0-mg group. In the 1.5-mg group, one participant with a history of arterial hypertension experienced two SAEs (cardiac failure and hypertensive heart disease), which the investigator judged to be possibly drug-related, whereas the sponsor deemed these SAEs unlikely to be related to the study drug. Another participant in the 1.5-mg group experienced three SAEs (contusion, dizziness, and fall) that were judged by the investigator as unlikely to be related to the study drug; however, the sponsor considered these events to be possibly related to the study drug. The remaining SAEs were considered by both the sponsor and the investigator to be either not related or unlikely related to the study drug. Except for the deceased participant, and one participant who recovered from cardiac events but also experienced intervertebral disc protrusion and recovered with sequelae (paraparesis of both legs), all participants in the $1.5-\mathrm{mg}$ and $3.0-\mathrm{mg}$ groups recovered or were still recovering from their SAEs at trial completion. During the post-treatment period ( 2 days after the 30-day follow-up period), one participant treated with $3.0 \mathrm{mg}$ esmirtazapine reported an SAE (hernia) that was not considered to be treatment-related.

There were no clinically meaningful changes in hematology parameters over the course of the study, with the exception of notable increases from baseline in both the percentage of eosinophils, which increased by a median of $16.7 \%$ and $20.4 \%$ with esmirtazapine $1.5 \mathrm{mg}$ and $3.0 \mathrm{mg}$, respectively, and absolute eosinophil counts, which increased by a median of $20.0 \%$ and $14.3 \%$ with esmirtazapine $1.5 \mathrm{mg}$ and $3.0 \mathrm{mg}$, respectively, over the course of the study. However, none of the abnormally high values were considered to be clinically significant. Although there were no clinically significant changes in mean or median values for biochemical parameters between baseline and the last measurement, there were some differences observed among treatment groups: higher median percentages of change from baseline were observed with the $3.0-\mathrm{mg}$ vs. the $1.5-\mathrm{mg}$ dose for alanine aminotransferase $(1.5 \mathrm{mg}$ : $0.0 \%$; $3.0 \mathrm{mg}: 5.4 \%$ ), aspartate aminotransferase (1.5 mg: $0.0 \% ; 3.0 \mathrm{mg}$ : 
2.0\%), total bilirubin (1.5 mg: 4.9\%; $3.0 \mathrm{mg}: 6.3 \%$ ), and glucose (1.5 mg: 3.9\%; $3.0 \mathrm{mg}: 10.3 \%$ ), and lower for gamma-glutamyl transferase (1.5 mg: 5.3\%; $3.0 \mathrm{mg}$ : 0.0\%). There were no clinically relevant changes in urinalysis, vital signs, or ECG parameters.

\section{Residual effects}

Based on the daytime functioning questionnaire in the weekly

Table 2. Safety profile of esmirtazapine

\begin{tabular}{|c|c|c|c|c|}
\hline & \multicolumn{2}{|c|}{$\begin{array}{c}\text { Esmirtazapine } 1.5 \mathrm{mg} \\
(\mathrm{n}=128 ; \mathrm{n}, \%)\end{array}$} & \multicolumn{2}{|c|}{$\begin{array}{c}\text { Esmirtazapine } 3.0 \mathrm{mg} \\
(\mathrm{n}=131 ; \mathrm{n}, \%)\end{array}$} \\
\hline \multicolumn{5}{|l|}{ Overall safety profile } \\
\hline Participants with AEs & \multicolumn{2}{|c|}{$115(89.8)$} & \multicolumn{2}{|c|}{$116(88.5)$} \\
\hline Deaths* & \multicolumn{2}{|c|}{$1(0.8)$} & \multicolumn{2}{|c|}{$0(0.0)$} \\
\hline Participants with SAEs ${ }^{\dagger}$ & \multicolumn{2}{|c|}{$9(7.0)$} & \multicolumn{2}{|c|}{$5(3.8)$} \\
\hline Participants who discontinued due to AEs & \multicolumn{2}{|c|}{$21(16.4)$} & \multicolumn{2}{|c|}{$24(18.3)$} \\
\hline Participants with drug-related $\mathrm{AEs}^{\ddagger}$ & \multicolumn{2}{|c|}{$74(57.8)$} & \multicolumn{2}{|c|}{$88(67.2)$} \\
\hline Participants with severe AEs & \multicolumn{2}{|c|}{$13(10.2)$} & \multicolumn{2}{|c|}{$14(10.7)$} \\
\hline AEs occurring in $\geq 2.5 \%$ of participants in any treatment group & Related & Total & Related & Total \\
\hline Somnolence & $15(11.7)$ & $15(11.7)$ & $33(25.2)$ & $35(26.7)$ \\
\hline Weight increased & $11(8.6)$ & $11(8.6)$ & $18(13.7)$ & $20(15.3)$ \\
\hline Dizziness & $8(6.3)$ & $12(9.4)$ & $14(10.7)$ & $19(14.5)$ \\
\hline Nasopharyngitis & $0(0.0)$ & $21(16.4)$ & $0(0.0)$ & $17(13.0)$ \\
\hline Fatigue & $15(11.7)$ & $17(13.3)$ & $11(8.4)$ & $15(11.5)$ \\
\hline Dry mouth & $9(7.0)$ & $10(7.8)$ & $12(9.2)$ & $14(10.7)$ \\
\hline Headache & $7(5.5)$ & $13(10.2)$ & $3(2.3)$ & $12(9.2)$ \\
\hline Increased appetite & $5(3.9)$ & $5(3.9)$ & $12(9.2)$ & $12(9.2)$ \\
\hline Back pain & $0(0.0)$ & $8(6.3)$ & $0(0.0)$ & $8(6.1)$ \\
\hline Hypertension & $0(0.0)$ & $3(2.3)$ & $1(0.8)$ & $11(8.4)$ \\
\hline Urinary tract infection & $0(0.0)$ & $2(1.6)$ & $1(0.8)$ & $10(7.6)$ \\
\hline Diarrhea & $1(0.8)$ & $7(5.5)$ & $4(3.1)$ & $9(6.9)$ \\
\hline Arthralgia & $0(0.0)$ & $6(4.7)$ & $1(0.8)$ & $9(6.9)$ \\
\hline Restless legs syndrome & $3(2.3)$ & $3(2.3)$ & $6(4.6)$ & $8(6.1)$ \\
\hline Influenza & $0(0.0)$ & $4(3.1)$ & $0(0.0)$ & $5(3.8)$ \\
\hline Nightmare & $3(2.3)$ & $3(2.3)$ & $5(3.8)$ & $6(4.6)$ \\
\hline Nausea & $1(0.8)$ & $3(2.3)$ & $3(2.3)$ & $6(4.6)$ \\
\hline Pain in extremity & $0(0.0)$ & $2(1.6)$ & $1(0.8)$ & $6(4.6)$ \\
\hline Upper respiratory tract infection & $0(0.0)$ & $3(2.3)$ & $0(0.0)$ & $4(3.1)$ \\
\hline Insomnia & $0(0.0)$ & $4(3.1)$ & $1(0.8)$ & $4(3.1)$ \\
\hline Oropharyngeal pain & $0(0.0)$ & $3(2.3)$ & $0(0.0)$ & $4(3.1)$ \\
\hline Sinusitis & $0(0.0)$ & $4(3.1)$ & $0(0.0)$ & $3(2.3)$ \\
\hline Constipation & $1(0.8)$ & $2(1.6)$ & $4(3.1)$ & $4(3.1)$ \\
\hline Hepatic enzyme increased & $0(0.0)$ & $0(0.0)$ & $2(1.5)$ & $4(3.1)$ \\
\hline Cough & $1(0.8)$ & $8(6.3)$ & $0(0.0)$ & $3(2.3)$ \\
\hline Sedation & $4(3.1)$ & $4(3.1)$ & $2(1.5)$ & $2(1.5)$ \\
\hline Abnormal dreams & $6(4.7)$ & $6(4.7)$ & $1(0.8)$ & $1(0.8)$ \\
\hline Upper abdominal pain & $2(1.6)$ & $4(3.1)$ & $0(0.0)$ & $1(0.8)$ \\
\hline
\end{tabular}

One participant had an SAE 2 days after the 30-day follow-up period; this participant is not counted in the table. *irrespective of time point of death, tincluding the fatal SAE, ‡relationship specified by the investigator as "Definite," "Probable," "Possible." AE: adverse event, SAE: serious $\mathrm{AE}$ 
Table 3. Summary statistics for residual effects parameters (allparticipants-treated population; last observation carried forward)

\begin{tabular}{ccc}
\hline \multirow{3}{*}{ Statistic } & \multicolumn{2}{c}{ Change from baseline to end of treatment } \\
\cline { 2 - 3 } & Esmirtazapine & Esmirtazapine \\
& $1.5 \mathrm{mg}(\mathrm{n}=128)$ & $3.0 \mathrm{mg}(\mathrm{n}=131)$ \\
\hline
\end{tabular}

Alertness at awakening

$\mathrm{n}$

Median (range)

17 (-71 to 97$)$

$15(-46$ to 88$)$

Mean (SD)

$18.3(29.2)$

$16.2(24.9)$

$p$-value

$<0.0001$

$<0.0001$

Feeling full of energy the past 7 days

$\begin{array}{lcc}\mathrm{n} & 123 & 128 \\ \text { Median (range) } & 13(-87 \text { to } 95) & 11(-58 \text { to } 83) \\ \text { Mean (SD) } & 16.1(27.7) & 13.6(24.3) \\ p \text {-value } & <0.0001 & <0.0001\end{array}$

VAS rating on ability to work/function

$\mathrm{n}$

123

128

Median (range)

$12(-77$ to 94$)$

$12(-50$ to 88$)$

Mean (SD)

$14.7(26.7)$

$<0.0001$

$14.6(23.1)$

$<0.0001$

Total nap time ( $\mathrm{min})$

\begin{tabular}{lcc}
$\mathrm{n}$ & 25 & 25 \\
Median (range) & $-1(-45.0$ to 40.0$)$ & $5(-120.0$ to 30.0$)$ \\
Mean (SD) & $-2.8(16.7)$ & $-0.9(27.4)$ \\
$p$-value & 0.4174 & 0.8737 \\
\hline
\end{tabular}

SD: standard deviation, VAS: visual analog scale diary, no residual effects were noted for either treatment group (Table 3, Supplementary Table 1 in the online-only Data Supplement). Instead, improvement was noted with an increase from baseline for alertness at awakening, level of energy, and ability to work/function. At end of treatment, the alertness score at awakening had increased from baseline by a median of 17 and 15 points for the $1.5-\mathrm{mg}$ and $3.0-\mathrm{mg}$ groups, respectively (based on LOCF data). Energy level score increased by a median of 13 (1.5-mg) and 11 (3.0-mg) points from baseline, and ability to work/function by 12 points (both dose groups). There was no significant change in nap time at end of treatment compared with baseline in either dose group.

\section{Efficacy}

Exploratory efficacy measures were determined by comparison of subjective sleep parameters (TST, WASO, and SL) recorded on Day 1 with those recorded at end of treatment (Table 4, Supplementary Table 2 in the online-only Data Supplement). Mean changes from baseline in weekly TST, WASO, and SL based on the primary analysis (using LOCF) and sensitivity analysis (based on OC data) are shown in Fig. 3 and Supplementary Fig. 1 (in the online-only Data Supplement), respectively, and median changes from baseline are described in the text. Results were consistent in both the OC and LOCF analyses for all sleep efficacy measures evaluated; therefore, the LOCF data are described below while the corresponding OC data are presented in the online-only Data Supplement.

Table 4. Summary statistics of SL, WASO, and TST at baseline and end of treatment (intent-to-treat population; last observation carried forward)

\begin{tabular}{|c|c|c|c|c|c|}
\hline \multirow{2}{*}{$\begin{array}{c}\text { Sleep characteristic } \\
(\mathrm{min})\end{array}$} & \multirow{2}{*}{ Time point } & \multicolumn{2}{|c|}{ Esmirtazapine $1.5 \mathrm{mg}(\mathrm{n}=128)$} & \multicolumn{2}{|c|}{ Esmirtazapine $3.0 \mathrm{mg}(\mathrm{n}=129)$} \\
\hline & & Mean (SD) & Median (range) & Mean (SD) & Median (range) \\
\hline \multicolumn{6}{|l|}{ Sleep duration } \\
\hline \multirow[t]{4}{*}{ TST } & $\mathrm{n}$ & 127 & 127 & 128 & 128 \\
\hline & Baseline & $294.0(71.0)$ & $300.0(150.0$ to 666.0$)$ & $293.5(67.3)$ & $300.0(0.0$ to 436.0$)$ \\
\hline & $\mathrm{n}$ & 124 & 124 & 129 & 129 \\
\hline & End of treatment & $381.0(82.5)$ & $390.0(120.0$ to 510.0$)$ & $380.4(99.1)$ & $390.0(6.0$ to 660.0$)$ \\
\hline \multicolumn{6}{|l|}{ Sleep maintenance } \\
\hline \multirow[t]{4}{*}{ WASO } & $\mathrm{n}$ & 127 & 127 & 128 & 128 \\
\hline & Baseline & $109.4(86.4)$ & $90.0(0.0$ to 660.0$)$ & $102.4(71.0)$ & $90.0(13.0$ to 540.0$)$ \\
\hline & $\mathrm{n}$ & 124 & 124 & 129 & 129 \\
\hline & End of treatment & $47.5(53.9)$ & $30.0(0.0$ to 360.0$)$ & $52.1(67.4)$ & $25.0(0.0$ to 360.0$)$ \\
\hline \multicolumn{6}{|l|}{ Sleep induction } \\
\hline \multirow[t]{4}{*}{ SL } & $\mathrm{n}$ & 127 & 127 & 128 & 128 \\
\hline & Baseline & $88.6(72.5)$ & $60.0(9.0$ to 480.0$)$ & $91.4(77.7)$ & $70.0(4.0$ to 360.0$)$ \\
\hline & $\mathrm{n}$ & 124 & 124 & 129 & 129 \\
\hline & End of treatment & $60.8(81.4)$ & $30.0(5.0$ to 445.0$)$ & $69.3(85.7)$ & $30.0(3.0$ to 450.0$)$ \\
\hline
\end{tabular}

SD: standard deviation, SL: sleep latency, TST: total sleep time, WASO: wake time after sleep onset 


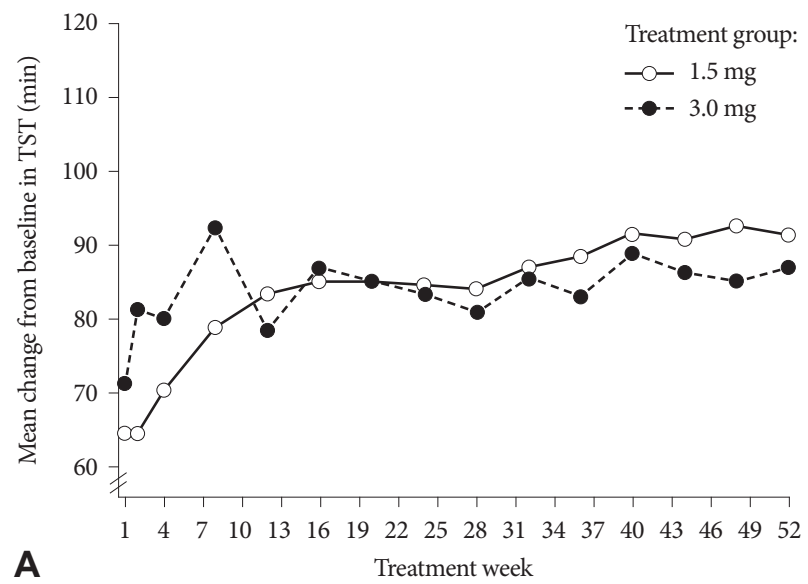

Treatment week

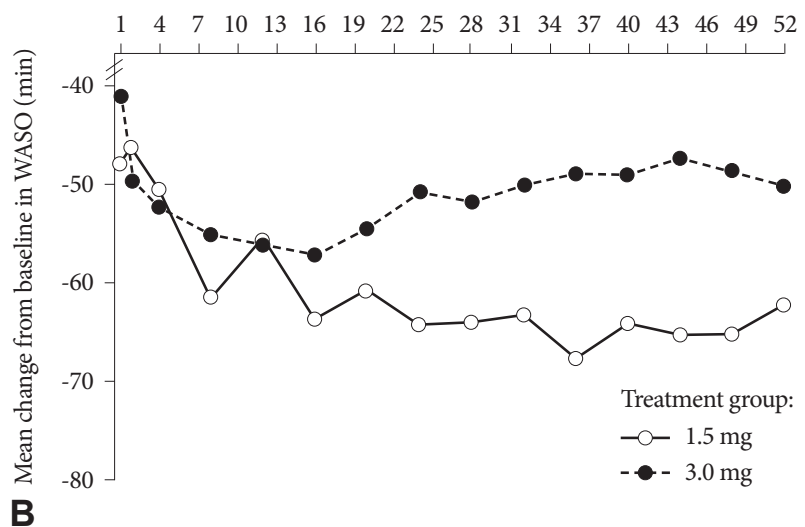

Treatment week

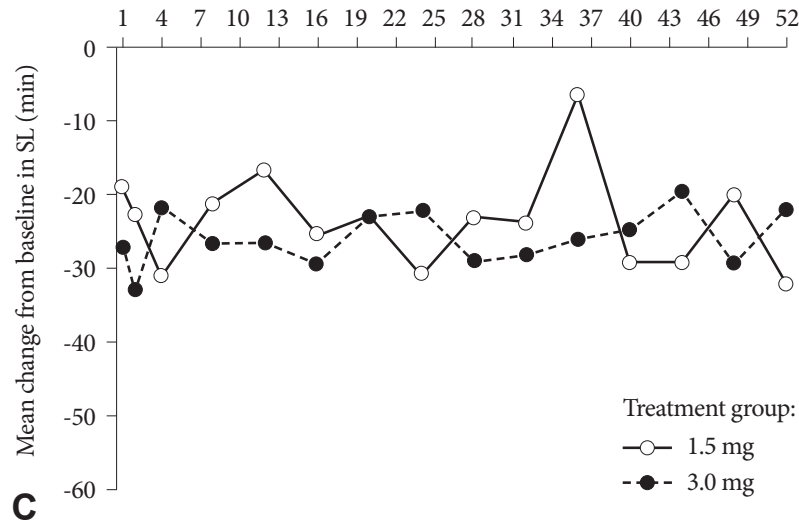

Figure 3. Mean change from baseline for weekly TST (A), WASO (B), and SL (C) in the intent-to-treat population (last observation carried forward). SL: sleep latency, TST: total sleep time, WASO: wake time after sleep onset.

At baseline, the median TST per night was $300.0 \mathrm{~min}$ for the 1.5-mg and 3.0-mg dose groups (Table 4). The TST improved during the 52-week treatment period for both groups, and at the end of treatment, both groups reported a TST time of $390.0 \mathrm{~min}$. The median change in TST from baseline to end of treatment was $90.0 \mathrm{~min}$ in both dose groups. The median subjective WASO at baseline was $90.0 \mathrm{~min}$ for both dose groups. There was an overall decline from baseline in WASO with both doses of esmirtazapine, and this decrease was more pronounced in the $1.5-\mathrm{mg}$ group than the $3.0-\mathrm{mg}$ group. At end of treatment, the median WASO was $30.0 \mathrm{~min}$ and $25.0 \mathrm{~min}$ for participants receiving esmirtazapine $1.5 \mathrm{mg}$ and $3.0 \mathrm{mg}$, respectively. The median decrease from baseline in WASO at end of treatment was $50.0 \mathrm{~min}$ and $38.0 \mathrm{~min}$ for the $1.5-\mathrm{mg}$ and $3.0-\mathrm{mg}$ groups, respectively. The median SL per night tended to decrease over the study, from $60 \mathrm{~min}$ and $70 \mathrm{~min}$ at baseline for participants receiving esmirtazapine $1.5 \mathrm{mg}$ and $3.0 \mathrm{mg}$, respectively, to $30 \mathrm{~min}$ in both dose groups at end of treatment. The median decrease from baseline was $25.0 \mathrm{~min}$ and $17.5 \mathrm{~min}$ in the 1.5-mg and 3.0-mg groups, respectively.

The median ISI total score at baseline was 18 for both the $1.5-\mathrm{mg}$ and $3.0-\mathrm{mg}$ esmirtazapine treatment groups. An improvement in ISI score from baseline to endpoint was observed for both treatment groups. At Week 52 (Visit 18), the median change from baseline in ISI was -9 and -11 for the $1.5-\mathrm{mg}$ and 3.0-mg treatment groups, respectively; at end of treatment, the median change from baseline in ISI was -8 for both treatment groups. Changes from baseline in ISI total score by visit/week are shown in Table 5 (OC data). Similarly, a significant improvement in IGR-S was observed at end of treatment relative to baseline in both treatment groups, indicating a lower severity of insomnia. The median change from baseline to end of treatment for IGR-S was -2 in both treatment groups. The response rate, defined as the percentage of participants with "marked" or "moderate" improvement, increased over time in both treatment groups, from $46.8 \%$ at Week 2 to $59.8 \%$ at end of study for participants receiving the $1.5-\mathrm{mg}$ dose, and from $61.7 \%$ to $64.3 \%$, respectively, for participants receiving the 3.0-mg dose.

Overall, the magnitude of change in the subjective efficacy variables was generally consistent throughout the 52 weeks of treatment, and no apparent difference between the $1.5-\mathrm{mg}$ and 3.0-mg treatment groups was observed.

\section{Discussion}

The current study examined the long-term safety of esmirtazapine in elderly patients with a diagnosis of chronic insomnia. The efficacy assessments were exploratory in nature, as no placebo comparator was included. The results indicate reasonable tolerability of both investigated doses of esmirtazapine $(1.5 \mathrm{mg}$ and $3.0 \mathrm{mg}$ ) administered before bedtime for the long-term treatment of elderly patients with insomnia. The exploratory efficacy data demonstrated a marked improvement from baseline in subjective sleep diary measures (i.e., TST, WASO, SL). Similarly, improvements from baseline were also noted in the ISI and IGR-S. These improvements from base- 
line were sustained over the 52-week treatment period and did not exhibit apparent differences between the two dose groups. The percentage of participants completing the current study

Table 5. Change from baseline for ISI total score by visit (intentto-treat population; observed cases)

\begin{tabular}{|c|c|c|}
\hline \multirow{3}{*}{ Statistic } & \multicolumn{2}{|c|}{ Change in total ISI score from baseline } \\
\hline & Esmirtazapine & Esmirtazapine \\
\hline & $1.5 \mathrm{mg}(\mathrm{n}=128)$ & $3.0 \mathrm{mg}(\mathrm{n}=129)$ \\
\hline \multicolumn{3}{|l|}{ Visit 5 (week 2) } \\
\hline $\mathrm{n}$ & 118 & 117 \\
\hline Median (range) & $-4(-21$ to 6$)$ & $-5(-20$ to 7$)$ \\
\hline Mean (SD) & $-4.7(5.0)$ & $-5.6(5.4)$ \\
\hline$p$-value & $<0.0001$ & $<0.0001$ \\
\hline \multicolumn{3}{|l|}{ Visit 6 (week 4) } \\
\hline $\mathrm{n}$ & 110 & 112 \\
\hline Median (range) & $-7(-17$ to 4$)$ & $-7(-21$ to 6$)$ \\
\hline Mean (SD) & $-6.5(4.9)$ & $-7.0(5.7)$ \\
\hline$p$-value & $<0.0001$ & $<0.0001$ \\
\hline \multicolumn{3}{|l|}{ Visit 8 (week 12) } \\
\hline $\mathrm{n}$ & 110 & 100 \\
\hline Median (range) & $-7(-19$ to 5$)$ & $-9(-22$ to 6$)$ \\
\hline Mean (SD) & $-7.7(6.0)$ & $-8.6(5.9)$ \\
\hline$p$-value & $<0.0001$ & $<0.0001$ \\
\hline \multicolumn{3}{|l|}{ Visit 11 (week 24) } \\
\hline $\mathrm{n}$ & 96 & 91 \\
\hline Median (range) & $-9(-21$ to 4$)$ & $-9(-25$ to 7$)$ \\
\hline Mean (SD) & $-8.5(5.9)$ & $-8.8(6.4)$ \\
\hline$p$-value & $<0.0001$ & $<0.0001$ \\
\hline \multicolumn{3}{|l|}{ Visit 14 (week 36) } \\
\hline $\mathrm{n}$ & 81 & 77 \\
\hline Median (range) & $-10(-20$ to 2$)$ & $-9(-22$ to 4$)$ \\
\hline Mean (SD) & $-9.4(5.5)$ & $-8.9(5.9)$ \\
\hline$p$-value & $<0.0001$ & $<0.0001$ \\
\hline \multicolumn{3}{|l|}{ Visit 18 (week 52) } \\
\hline $\mathrm{n}$ & 70 & 68 \\
\hline Median (range) & $-9(-22$ to 6$)$ & $-11(-21$ to 4$)$ \\
\hline Mean (SD) & $-8.9(6.4)$ & $-10.3(5.8)$ \\
\hline$p$-value & $<0.0001$ & $<0.0001$ \\
\hline \multicolumn{3}{|l|}{ Endpoint } \\
\hline $\mathrm{n}$ & 122 & 123 \\
\hline Median (range) & $-8(-22$ to 6$)$ & $-8(-25$ to 7$)$ \\
\hline Mean (SD) & $-7.5(6.6)$ & $-7.5(6.9)$ \\
\hline$p$-value & $<0.0001$ & $<0.0001$ \\
\hline
\end{tabular}

$p$-value: performed for change from baseline within treatment based on t-statistics, baseline: the last observation before study treatment. ISI: insomnia severity index, SD: standard deviation
(59.1\%) was comparable with the completion rate (65.4\%) of a 1-year, open-label, extension phase of two randomized trials of zaleplon. $^{35}$

The safety of 1.5-mg, 3.0-mg, and 4.5-mg doses of esmirtazapine was previously examined for a shorter duration of treatment and in a younger population of adult patients with insomnia (aged $\leq 65$ years). ${ }^{31,32,34}$ In these studies, esmirtazapine was well tolerated with minimal residual effects. The incidence of AEs and SAEs was higher in the current study relative to previously published studies of esmirtazapine treatment in non-elderly patients with primary insomnia. ${ }^{31,32}$ In a 2-week study in non-elderly patients, $25.5 \%$ and $32.8 \%$ of patients had AEs, and $1.5 \%$ and $0.8 \%$ had SAEs, with esmirtazapine $1.5 \mathrm{mg}$ and $3.0 \mathrm{mg}$, respectively. In a 6-week study in non-elderly patients, $35.3 \%$ of patients had AEs following esmirtazapine $3.0 \mathrm{mg}$ administration. No SAEs were reported with esmirtazapine 3.0-mg in the 6-week study. However, cross-study comparisons should be interpreted with caution due to the differences in study design and participant population. Consistent with previous findings from 2- and 6-week studies of esmirtazapine treatment in non-elderly patients, the current study results indicate that somnolence was among the most commonly reported AEs. This effect did not seem to interfere with overall daily functioning as assessed by the weekly diary, given the sustained improvements in scores of alertness at awakening, energy level, and the ability to work/function throughout the treatment period as compared with baseline. Increase in body weight was also a frequently recorded $\mathrm{AE}$ (8.6\% and $15.3 \%$ in the $1.5-\mathrm{mg}$ and $3.0-\mathrm{mg}$ groups, respectively). This is not surprising, given that this side effect has been previously associated with mirtazapine treatment for depression ${ }^{36,37}$ and was attributed to its mechanism of action, which is based on the blockade of $\mathrm{H1}$, and $5-\mathrm{HT}_{2}$, and $5-\mathrm{HT}_{3}$ receptors. ${ }^{29}$

The fall rate observed in this study was relatively low: three participants $(2.3 \%)$ receiving a dose of $1.5 \mathrm{mg}$ esmirtazapine reported a fall. While treatment of insomnia symptoms in elderly patients frequently leads to the prescription of $\mathrm{GABA}_{\mathrm{A}}$ receptor modulators, ${ }^{38}$ this population is more sensitive to the AEs of such therapeutic agents: it is reported that one in seven elderly patients treated with benzodiazepines will have an AE. ${ }^{39}$ One study reported that $40 \%$ of elderly patients admitted for emergency care after a fall had been prescribed benzodiazepines and Z-drugs. ${ }^{40}$ Furthermore, compared with other times, it is reported that the fall risk for nursing-home residents is greater (odds ratio 3.79; 95\% confidence interval 1.10-13.00) within $24 \mathrm{~h}$ of benzodiazepine administration. ${ }^{41}$ Increased caution when prescribing Z-drugs for long-term treatment of insomnia in the geriatric population is, therefore, recommended. ${ }^{42}$ The relatively low fall rate observed for esmirtazapine in 
the current study is of interest; however, study limitations should be taken into consideration.

Discontinuation due to insufficient therapeutic effect appeared to occur more frequently in the $3.0-\mathrm{mg}$ group than the $1.5-\mathrm{mg}$ group. Although the small sample size limits the ability to draw conclusions regarding this finding, and a definitive explanation is therefore unclear, greater residual effects at the higher dose, which may have diminished participants' interpretations of efficacy, may have contributed. This may be supported by the observation that approximately twice the number of participants in the 3.0-mg group reported somnolence and dizziness compared with the 1.5-mg group. Lack of compliance with taking medication per protocol could be another contributing factor; however, cumulative compliance in this study was $95.8 \%$ for the $3.0-\mathrm{mg}$ group and $97.6 \%$ for the 1.5 -mg group, and is unlikely to fully explain the difference.

The observation that both doses of esmirtazapine showed no apparent deleterious effects on measures of alertness at awakening, energy level, and ability to work/function (as captured with the sleep diary) is consistent with data from previous studies that have assessed the potential for next-day hangover effects from esmirtazapine in non-elderly adults with insomnia. ${ }^{31,32}$ Following a 2-week treatment with esmirtazapine $(1.5 \mathrm{mg}$, $3.0 \mathrm{mg}$, and $4.5 \mathrm{mg}$ ), there was no evidence of residual effects in the esmirtazapine groups. ${ }^{31} \mathrm{~A}$ 6-week treatment with esmirtazapine also demonstrated minimal residual next-day effect, as evaluated by a digit symbol substitution test, VAS score for morning alertness, and the Bond-Lader rating scale. ${ }^{32}$ In another study that evaluated effects of an acute, 2-day treatment of esmirtazapine in patients with insomnia, a decrease in energy level and ability to work/function was experienced after the first night compared with placebo; however, this effect was not reported after the second night. ${ }^{34}$ In the current study, both treatment groups showed improvement from baseline in alertness at awakening and energy levels, as assessed by the weekly diary, and both esmirtazapine doses provided similar median changes from baseline for both parameters. Sedation has been reported for mirtazapine, ${ }^{43}$ although no evidence of next-day sedation was observed among patients with major depressive disorder treated with mirtazapine $(45 \mathrm{mg})$ as compared with those treated with fluoxetine (A Winokur, personal communication). A study assessing the effects of esmirtazapine $1.5 \mathrm{mg}$ and $4.5 \mathrm{mg}$ on next-day driving performance showed that single and repeated administration of esmirtazapine $1.5 \mathrm{mg}$ had no clinically meaningful effects on driving performance. With a single dose of esmirtazapine $4.5 \mathrm{mg}$, driving impairment was observed; however, this resolved following repeated dosing. ${ }^{33} \mathrm{~A}$ lack of prominent morning sedation observed with esmirtazapine in this study may be of interest to psychiatrists.
Previous reports on the efficacy of esmirtazapine in non-elderly adult patients with primary insomnia have indicated sustained beneficial effects on objective and subjective patient-reported measures of sleep onset and maintenance over the study period. ${ }^{31,32,34}$ However, the examined treatment durations did not exceed 6 weeks, which does not reflect the long-term course of therapy that might be required when treating patients with chronic insomnia. The results of the present study suggest that esmirtazapine has enduring sleep-promoting effects in elderly patients over a period of 52 weeks, and that these effects did not appear to be accompanied by the development of tolerance. This is supported by the marked improvements in TST, WASO, SL, ISI, and IGR-S values compared with baseline at each of the assessments conducted throughout the study.

The apparent sleep-promoting properties of esmirtazapine should be considered in the context of long-term efficacy data of other pharmacological treatments for insomnia. While benzodiazepines have established short-term benefits with regard to improvement in sleep initiation and maintenance, their longterm efficacy has not been established. ${ }^{26}$ As such, they are recommended for short-term use, with continued use believed to be associated with tolerance. ${ }^{26}$ Long-term use of non-benzodiazepines has been more rigorously tested in clinical trials. For example, in a randomized, double-blind, placebo-controlled study, nighttime use of eszopiclone in patients (aged 21-69 years) with chronic insomnia demonstrated efficacy over a 6-month period. ${ }^{44}$ Similar to the sustained improvements in TST, WASO, and SL over the year-long period of the current study, the authors reported that the median SL and WASO decreased from baseline by $30 \mathrm{~min}$ and $39 \mathrm{~min}$, respectively, and median TST increased from baseline by 83 min after 6 months. ${ }^{44}$ Similarly, zolpidem extended-release $(12.5 \mathrm{mg})$ was well tolerated in non-elderly adults (aged 18-64 years) and improved sleep onset and maintenance parameters compared with placebo in a 6-month randomized, double-blind, placebo-controlled, multicenter study. ${ }^{45}$ In elderly patients (aged 59-95 years) with insomnia, nightly zaleplon (5 $\mathrm{mg}$ and $10 \mathrm{mg}$ ) was associated with sustained improvements in sleep onset, sleep duration, and number of awakenings in a year-long, open-label extension study. ${ }^{35}$ However, it should be noted that relatively few studies have reported the systematic monitoring of TST, WASO, and SL parameters over a comparably long time period, and this, combined with differences in trial design, limits the ability to draw direct comparisons with other therapeutics. The current study highlights the need for systematic assessment of longterm treatment effects of drugs for insomnia.

Several limitations should be considered when interpreting the findings of this study. The study design did not include a non-active (placebo) treatment arm and participants were only blinded to the dose of treatment they received, which limits ef- 
ficacy evaluation. The contribution of factors other than drug activity to the frequency of AEs and reported therapeutic effect cannot, therefore, be excluded. Also, the sample size of the study was not determined by power analysis for detecting a significant difference at a fixed, Type I error rate. As a result, there was no formal hypothesis formulation and testing in this study. The study was only designed to assess within-group statistical differences relative to baseline values-not differences between the dose groups. Although there were no apparent differences between the two dose groups with regard to exploratory efficacy outcomes, dose-response measurements were not collected for this study, so only a tentative statement regarding the lack of apparent dose-response effects of esmirtazapine in improving insomnia sleep parameters long-term can be made. Finally, co-occurrence of insomnia with anxiety and/or depression is prevalent in the elderly population, and patients with such comorbidities were excluded from this study. This limits the generalizability of the findings and warrants further research efforts in patients with comorbid insomnia to establish the safety and efficacy of esmirtazapine in these subpopulations.

Our findings suggest that esmirtazapine doses of $1.5 \mathrm{mg}$ and $3.0 \mathrm{mg}$ nightly are reasonably tolerated in elderly outpatients with insomnia as long-term treatment (up to 1 year) without evidence of significant residual effects. Despite the lack of placebo and the limited power of the analysis, the persistent improvements in sleep parameters throughout this year-long study in elderly patients are encouraging, especially when considering tolerance issues associated with the long-term use of many hypnotics.

\section{Supplementary Materials}

The online-only Data Supplement is available with this article at https:// doi.org/10.13078/jsm.190032.

\section{Acknowledgments}

Funding for this research was provided by Organon, a subsidiary of Merck \& Co., Inc., Kenilworth, NJ, USA. The study sponsor was involved in the: design of the study; collection, analysis, and interpretation of the data; preparation of the manuscript; and decision to submit the manuscript for publication. Medical writing support, under the direction of the authors, was provided by Hicham Naimy, PhD, and Adele Blair, $\mathrm{PhD}$, of CMC AFFINITY, McCann Health Medical Communications, funded by Merck Sharp \& Dohme Corp., a subsidiary of Merck \& Co., Inc., Kenilworth, NJ, USA, in accordance with Good Publication Practice (GPP3) guidelines. The authors would like to thank Armin Szegedi, Thomas Roth, and Bernhard Slaap for contributions to the study design and for helpful discussion.

\section{Conflicts of Interest}

NI-M, QC, and AP are current or former employees of Merck Sharp \& Dohme Corp., a subsidiary of Merck \& Co., Inc., Kenilworth, NJ, USA, and may own stock and/or stock options in Merck \& Co., Inc., Kenilworth, NJ, USA. AW received research funding and personal fees from Merck
Sharp \& Dohme Corp., a subsidiary of Merck \& Co., Inc., Kenilworth, NJ, USA for the conduct of the study at UConn Health, Farmington, CT, USA.

\section{ORCID iDs}

$\begin{array}{ll}\text { Neely Ivgy-May } & \text { https://orcid.org/0000-0001-5155-4343 } \\ \text { Qing Chang } & \text { https://orcid.org/0000-0003-3391-0310 } \\ \text { Annpey Pong } & \text { https://orcid.org/0000-0002-3377-5318 } \\ \text { Andrew Winokur } & \text { https://orcid.org/0000-0003-2859-9361 }\end{array}$

\section{Author Contributions}

Conceptualization: Neely Ivgy-May, Qing Chang. Data curation: Andrew Winokur. Formal analysis: Neely Ivgy-May, Annpey Pong. Investigation: Andrew Winokur. Methodology: Neely Ivgy-May, Qing Chang. Supervision: Neely Ivgy-May. Writing—original draft: Neely Ivgy-May, Qing Chang, Annpey Pong, Andrew Winokur. Writing_review \& editing: Neely Ivgy-May, Qing Chang, Annpey Pong, Andrew Winokur.

\section{REFERENCES}

1. American Psychiatric Association. Diagnostic and statistical manual of mental disorders, fourth edition, text revision (DSM-IV-TR ${ }^{\circledR}$ ). Washington, DC: American Psychiatric Association Publishing, 2010.

2. Roth T, Coulouvrat C, Hajak G, et al. Prevalence and perceived health associated with insomnia based on DSM-IV-TR; International Statistical Classification of diseases and related health problems, tenth revision; and Research Diagnostic Criteria/International Classification of Sleep Disorders, second edition criteria: results from the America Insomnia Survey. Biol Psychiatry 2011;69:592-600.

3. Drake CL, Roehrs T, Roth T. Insomnia causes, consequences, and therapeutics: an overview. Depress Anxiety 2003;18:163-176.

4. Kucharczyk ER, Morgan K, Hall AP. The occupational impact of sleep quality and insomnia symptoms. Sleep Med Rev 2012;16:547-559.

5. Thase ME. Correlates and consequences of chronic insomnia. Gen Hosp Psychiatry 2005;27:100-112.

6. Scharf M, Erman M, Rosenberg R, et al. A 2-week efficacy and safety study of eszopiclone in elderly patients with primary insomnia. Sleep 2005;28:720-727.

7. Vermeeren A, Vets E, Vuurman EF, et al. On-the-road driving performance the morning after bedtime use of suvorexant 15 and $30 \mathrm{mg}$ in healthy elderly. Psychopharmacology (Berl) 2016;233:3341-3351.

8. Sivertsen B, Omvik S, Pallesen S, et al. Cognitive behavioral therapy vs zopiclone for treatment of chronic primary insomnia in older adults: a randomized controlled trial. JAMA 2006;295:2851-2858.

9. Brassington GS, King AC, Bliwise DL. Sleep problems as a risk factor for falls in a sample of community-dwelling adults aged 64-99 years. J Am Geriatr Soc 2000;48:1234-1240.

10. Krishnan P, Hawranik P. Diagnosis and management of geriatric insomnia: a guide for nurse practitioners. J Am Acad Nurse Pract 2008; 20:590-599.

11. Krystal AD. New developments in insomnia medications of relevance to mental health disorders. Psychiatr Clin North Am 2015;38:843-860.

12. Schutte-Rodin S, Broch L, Buysse D, Dorsey C, Sateia M. Clinical guideline for the evaluation and management of chronic insomnia in adults. J Clin Sleep Med 2008;4:487-504.

13. Roehrs T, Roth T. Insomnia pharmacotherapy. Neurotherapeutics 2012; 9:728-738.

14. Glass J, Lanctôt KL, Herrmann N, Sproule BA, Busto UE. Sedative hypnotics in older people with insomnia: meta-analysis of risks and benefits. BMJ 2005;331:1169.

15. Salzman C. Pharmacologic treatment of disturbed sleep in the elderly. Harv Rev Psychiatry 2008;16:271-278.

16. Gotter AL, Webber AL, Coleman PJ, Renger JJ, Winrow CJ. International Union of Basic and Clinical Pharmacology. LXXXVI. Orexin receptor function, nomenclature and pharmacology. Pharmacol Rev 2012; 
64:389-420

17. Herring WJ, Connor KM, Ivgy-May N, et al. Suvorexant in patients with insomnia: results from two 3-month randomized controlled clinical trials. Biol Psychiatry 2016;79:136-148.

18. Herring WJ, Connor KM, Snyder E, et al. Suvorexant in elderly patients with insomnia: pooled analyses of data from phase III randomized controlled clinical trials. Am J Geriatr Psychiatry 2017;25:791-802.

19. Michelson D, Snyder E, Paradis E, et al. Safety and efficacy of suvorexant during 1-year treatment of insomnia with subsequent abrupt treatment discontinuation: a phase 3 randomised, double-blind, placebocontrolled trial. Lancet Neurol 2014;13:461-471.

20. Vermeeren A, Sun H, Vuurman EF, et al. On-the-road driving performance the morning after bedtime use of suvorexant 20 and $40 \mathrm{mg}$ : a study in non-elderly healthy volunteers. Sleep 2015;38:1803-1813.

21. Doghramji PP. Integrating modern concepts of insomnia and its contemporary treatment into primary care. Postgrad Med 2014;126:82101.

22. Stahl SM. Selective histamine H1 antagonism: novel hypnotic and pharmacologic actions challenge classical notions of antihistamines. CNS Spectr 2008;13:1027-1038.

23. U.S. Food and Drug Administration. Silenor (Doxepin) label [prescribing information] (2010). [cited 2019 Jan 16]. URL:https://www. accessdata.fda.gov/drugsatfda_docs/label/2010/022036lbl.pdf. Accessed 2019 Dec 19

24. Krystal AD, Lankford A, Durrence HH, et al. Efficacy and safety of doxepin 3 and $6 \mathrm{mg}$ in a 35-day sleep laboratory trial in adults with chronic primary insomnia. Sleep 2011;34:1433-1442.

25. Krystal AD, Durrence HH, Scharf M, et al. Efficacy and safety of doxepin $1 \mathrm{mg}$ and $3 \mathrm{mg}$ in a 12-week sleep laboratory and outpatient trial of elderly subjects with chronic primary insomnia. Sleep 2010;33:15531561.

26. Asnis GM, Thomas M, Henderson MA. Pharmacotherapy treatment options for insomnia: a primer for clinicians. Int J Mol Sci 2015;17:50.

27. Cluydts RJ, Hajak G, De Weerd A, Janssens C, Ruwe F. Significant effects on sleep of low dose mirtazapine in patients with primary insomnia. Sleep 2003;26:A81 [0200.c].

28. Winokur A, DeMartinis NA 3rd, McNally DP, Gary EM, Cormier JL, Gary KA. Comparative effects of mirtazapine and fluoxetine on sleep physiology measures in patients with major depression and insomnia. J Clin Psychiatry 2003;64:1224-1229.

29. Enomoto T, Yamashita A, Torigoe K, et al. Effects of mirtazapine on sleep disturbance under neuropathic pain-like state. Synapse 2012;66: 483-488.

30. U.S. Food and Drug Administration. Remeron (mirtazapine) tablets [package insert] (2017). [cited 2019 Jan 16]. URL:https://www.accessdata.fda.gov/drugsatfda_docs/label/2007/020415s019,021208s010lbl. pdf. Accessed 2019 Dec 19.

31. Ivgy-May N, Roth T, Ruwe F, Walsh J. Esmirtazapine in non-elderly adult patients with primary insomnia: efficacy and safety from a 2-week randomized outpatient trial. Sleep Med 2015;16:831-837.

32. Ivgy-May N, Ruwe F, Krystal A, Roth T. Esmirtazapine in non-elderly adult patients with primary insomnia: efficacy and safety from a randomized, 6-week sleep laboratory trial. Sleep Med 2015;16:838-844.

33. Ramaekers JG, Conen S, de Kam PJ, et al. Residual effects of esmirtazapine on actual driving performance: overall findings and an exploratory analysis into the role of CYP2D6 phenotype. Psychopharmacology (Berl) 2011;215:321-332.

34. Ruwe F, IJzerman-Boon P, Roth T, Zammit G, Ivgy-May N. A phase 2 randomized dose-finding study with esmirtazapine in patients with primary insomnia. J Clin Psychopharmacol 2016;36:457-464.

35. Ancoli-Israel S, Richardson GS, Mangano RM, Jenkins L, Hall P, Jones WS. Long-term use of sedative hypnotics in older patients with insomnia. Sleep Med 2005;6:107-113.

36. Masand PS, Gupta S. Long-term side effects of newer-generation antidepressants: SSRIS, venlafaxine, nefazodone, bupropion, and mirtazapine. Ann Clin Psychiatry 2002;14:175-182.

37. Watanabe N, Omori IM, Nakagawa A, et al. Mirtazapine versus other antidepressive agents for depression. Cochrane Database Syst Rev 2011; (12):CD006528.

38. Markota M, Rummans TA, Bostwick JM, Lapid MI. Benzodiazepine use in older adults: dangers, management, and alternative therapies. Mayo Clin Proc 2016;91:1632-1639.

39. Sithamparanathan K, Sadera A, Leung L. Adverse effects of benzodiazepine use in elderly people: a meta-analysis. Asian J Gerontol Geriatr 2012;7:107-111.

40. Martinez-Cengotitabengoa M, Diaz-Gutierrez MJ, Besga A, et al. Benzodiazepine prescriptions and falls in older men and women. Rev Psiquiatr Salud Ment 2018;11:12-18.

41. Berry SD, Placide SG, Mostofsky E, et al. Antipsychotic and benzodiazepine drug changes affect acute falls risk differently in the nursing home. J Gerontol A Biol Sci Med Sci 2016;71:273-278.

42. McMillan JM, Aitken E, Holroyd-Leduc JM. Management of insomnia and long-term use of sedative-hypnotic drugs in older patients. CMAJ 2013;185:1499-1505.

43. Mayers AG, Baldwin DS. Antidepressants and their effect on sleep. Hum Psychopharmacol 2005;20:533-559.

44. Krystal AD, Walsh JK, Laska E, et al. Sustained efficacy of eszopiclone over 6 months of nightly treatment: results of a randomized, doubleblind, placebo-controlled study in adults with chronic insomnia. Sleep 2003;26:793-799.

45. Krystal AD, Erman M, Zammit GK, Soubrane C, Roth T; ZOLONG Study Group. Long-term efficacy and safety of zolpidem extended-release $12.5 \mathrm{mg}$, administered 3 to 7 nights per week for 24 weeks, in patients with chronic primary insomnia: a 6-month, randomized, double-blind, placebo-controlled, parallel-group, multicenter study. Sleep 2008;31:79-90. 
Supplementary Table 1. Summary statistics for residual effects parameters (all-participants-treated population; observed case)

\begin{tabular}{lcc}
\hline \multirow{2}{*}{ Statistic } & \multicolumn{2}{c}{ Change from baseline to end of treatment } \\
\cline { 2 - 3 } & Esmirtazapine & Esmirtazapine \\
& $1.5 \mathrm{mg}(\mathrm{n}=128)$ & $3.0 \mathrm{mg}(\mathrm{n}=131)$ \\
\hline Alertness at awakening & & \\
$\mathrm{n}$ & 123 & 128 \\
Median (range) & $17(-71$ to 97$)$ & $15(-46$ to 88$)$ \\
Mean (SD) & $18.3(29.2)$ & $16.2(24.9)$ \\
$p$-value & $<0.0001$ & $<0.0001$ \\
Feeling full of energy the past 7 days & \\
$\mathrm{n}$ & 123 & 128 \\
Median (range) & $13(-87$ to 95$)$ & $11(-58$ to 83$)$ \\
Mean (SD) & $16.1(27.7)$ & $13.6(24.3)$ \\
$p$-value & $<0.0001$ & $<0.0001$ \\
VAS rating on ability to work/function & \\
$\mathrm{n}$ & 123 & 128 \\
Median (range) & $12(-77$ to 94$)$ & $12(-50$ to 88$)$ \\
Mean (SD) & $14.7(26.7)$ & $14.6(23.1)$ \\
$p$-value & $<0.0001$ & $<0.0001$ \\
Total nap time (min) & & $-0.9(27.4)$ \\
$\mathrm{n}$ & 25 & 0.8737 \\
Median (range) & $-1(-45.0$ to 40.0$)$ & $5(-120.0$ to 30.0$)$ \\
Mean (SD) & $-2.8(16.7)$ & 0.4174 \\
$p$-value & & \\
\hline
\end{tabular}

SD: standard deviation, VAS: visual analog scale 
Supplementary Table 2. Summary statistics of SL, WASO, number of enquiries, and TST at baseline and end of treatment (intent-totreat population; observed case)

\begin{tabular}{|c|c|c|c|c|c|}
\hline \multirow{2}{*}{$\begin{array}{l}\text { Sleep characteristic } \\
(\min )\end{array}$} & \multirow{2}{*}{ Time point } & \multicolumn{2}{|c|}{ Esmirtazapine $1.5 \mathrm{mg}(\mathrm{n}=128)$} & \multicolumn{2}{|c|}{ Esmirtazapine $3.0 \mathrm{mg}(\mathrm{n}=129)$} \\
\hline & & Mean (SD) & Median (range) & Mean $(\mathrm{SD})$ & Median (range) \\
\hline \multicolumn{6}{|l|}{ Sleep duration } \\
\hline \multirow[t]{4}{*}{ TST } & $\mathrm{n}$ & 127 & 127 & 128 & 128 \\
\hline & Baseline & $294.0(71.0)$ & $300.0(150.0$ to 666.0$)$ & $293.5(67.3)$ & $300.0(0.0$ to 436.0$)$ \\
\hline & $\mathrm{n}$ & 124 & 124 & 129 & 129 \\
\hline & End of treatment & $381.0(82.5)$ & $390.0(120.0$ to 510.0$)$ & $380.4(99.1)$ & $390.0(6.0$ to 660.0$)$ \\
\hline \multicolumn{6}{|l|}{ Sleep maintenance } \\
\hline \multirow[t]{4}{*}{ WASO } & $\mathrm{n}$ & 127 & 127 & 128 & 128 \\
\hline & Baseline & $109.4(86.4)$ & $90.0(0.0$ to 660.0$)$ & $102.4(71.0)$ & $90.0(13.0$ to 540.0$)$ \\
\hline & $\mathrm{n}$ & 124 & 124 & 129 & 129 \\
\hline & End of treatment & $47.5(53.9)$ & $30.0(0.0$ to 360.0$)$ & $52.1(67.4)$ & $25.0(0.0$ to 360.0$)$ \\
\hline \multicolumn{6}{|l|}{ Sleep induction } \\
\hline \multirow[t]{4}{*}{ SL } & $\mathrm{n}$ & 127 & 127 & 127 & 128 \\
\hline & Baseline & $88.6(72.5)$ & $60.0(9.0$ to 480.0$)$ & $91.4(77.7)$ & $70.0(4.0$ to 36.0$)$ \\
\hline & $\mathrm{n}$ & 124 & 124 & 129 & 129 \\
\hline & End of treatment & $60.8(81.4)$ & $30.0(5.0$ to 445.0$)$ & $69.3(85.7)$ & $30.0(3.0$ to 450.0$)$ \\
\hline
\end{tabular}

SD: standard deviation, SL: sleep latency, TST: total sleep time, WASO: wake time after sleep onset 


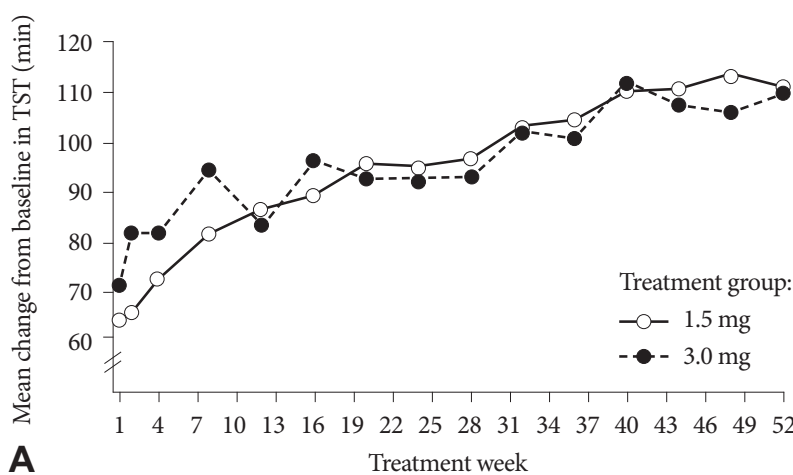

Treatment week

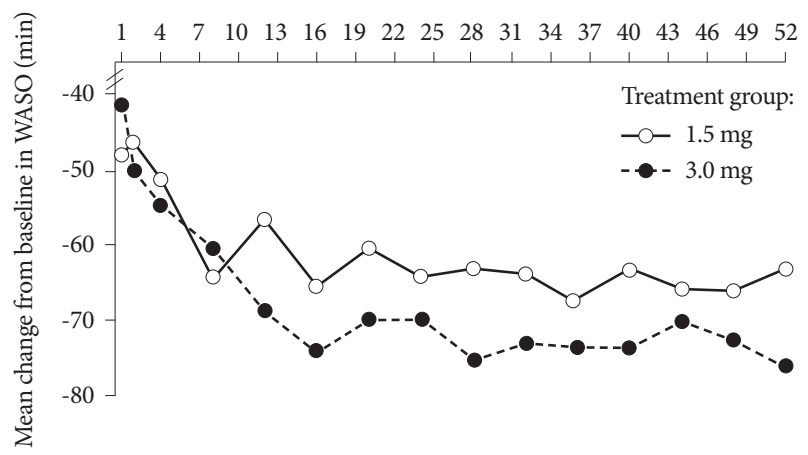

B

Treatment week

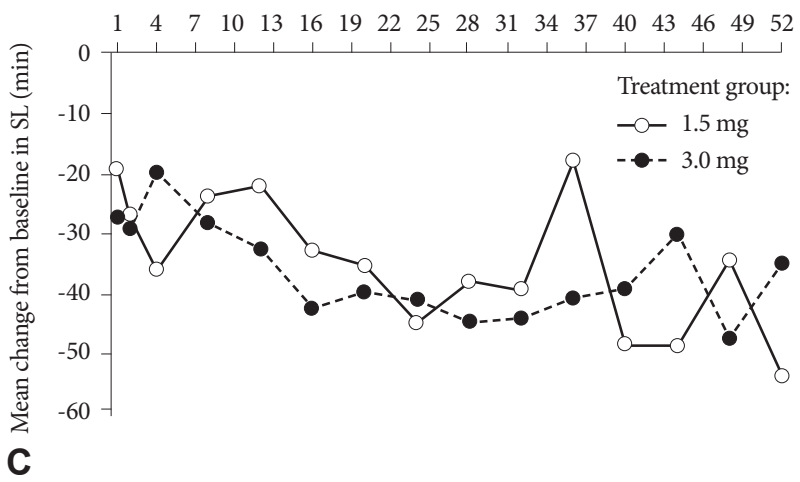

Supplementary Figure 1. Mean change from baseline for weekly TST (A), WASO (B), and SL (C) in the intent-to-treat population (observed case). SL: sleep latency, TST: total sleep time, WASO: wake time after sleep onset. 